\title{
Interactive comment on "Satellite Hydrology Observations as Operational Indicators of Forecasted Fire Danger across the Contiguous United States" by Alireza Farahmand et al.
}

\section{Anonymous Referee \#1}

Received and published: 6 June 2019

Overall assessment The current manuscript presents new research regarding the longterm assessment of fire danger based on hydrological data. Overall, it is an interesting study and the manuscript itself is well written. There are some points that could be improved, as highlighted in the following.

Minor comments Section 2.1: In its current form, this section would be more suited to a technical report document, rather than to a scientific publication. I would appreciate it if the authors revised their text, avoiding the bullet-style format. L115: Is there any reference that could be used for supporting the statement that GACCs exhibit similar fire weather types? Table 1: Discussion of results should be removed from the legend

Printer-friendly version

Discussion paper 
of the Table, which should only provide information about the data presented. L219222: Some references on the different behavior of different vegetation types would NHESSD enhance the statement made here. L229-236: This paragraph is mostly a repetition from the Introduction. I believe it does not add anything to the discussion and could be thus removed.

Technical remarks L56: "far away" L70: "Behrangi et al. (2016)" L85: "hypothesis" Fig. 1 : Please, annotate the different panels of the figure (a, b, c, ..) Equations: Please, number all the equations present in the manuscript. Section "Results" is not numbered. Same for "Discussion and Conclusions". L166: "evergreen vegetation". L172,175: "herbaceous vegetation". L184: "worst" instead of "least".

Interactive comment on Nat. Hazards Earth Syst. Sci. Discuss., https://doi.org/10.5194/nhess2019-129, 2019.

Printer-friendly version

Discussion paper 